\title{
“HABRÁ VIEJO MAS MORLACO? VAYASE Á TOMAR TABACO". \\ MORAL Y MEDICINA: CONCEPTOS Y USOS \\ (SIGLOS XVII-XVIII)
}

\section{"IS THERE OLDMAN MORE BULLISH? GO TAKE TOBACCO". \\ MORALS AND MEDICINE: CONCEPTS AND USES (17 ${ }^{\text {th }}-18^{\text {th }}$ CENTURIES)}

\author{
JoÃo Figueiroa-Rego \\ $\mathrm{CHAM} / \mathrm{FCSH}$ \\ Universidade Nova de Lisboa
}

\section{RESUMEN}

La proliferación del uso de tabaco a lo largo de los siglos XVII y XVIII ha generado un conjunto de trabajos literarios en los que se mezclan conceptos morales y normas médicas. Algunos de esos textos nos hacen sonreír ante la ingenuidad e ignorancia de una realidad cuyas consecuencias aún eran poco conocidas. Si para algunos el consumo de tabaco era inmoral y dañino, por lo tanto, demonizado, para otros autores sería no un vicio sino un recurso que podía contribuir con éxito para el tratamiento de enfermedades.

Palabras clave: moral, medicina, tabaco, autores, conceptos y usos.

\begin{abstract}
The proliferation of tobacco use during the 17th and 18th centuries has generated a lot of literary works in which moral concepts and medical norms are mixed. Today, some of these texts make us smile due to the naivety and ignorance of a reality whose consequences were still little known. If for some, tobacco use was immoral and harmful, therefore demonized, for other authors it would be not a vice but a resource that could successfully contribute to the treatment of diseases.
\end{abstract}

Keywords: moral, medicine, tobacco, writers, concepts, uses. 


\section{RESUM \\ "HABRÁ VIEJO MAS MORLACO? VAYASE Á TOMAR TABACO". MORAL I MEDICINA: CONCEPTES I USOS (SEGLES XVII-XVIII)}

La proliferació de l'ús del tabac tot al llarg dels segles XVII i XVIII ha generat un conjunt de treballs literaris en els quals es barregen conceptes morals i normes mèdiques. Alguns d'aquests texts ens fan traure un somriure davant la ingenuïtat i ignorància d'una realitat que tenia conseqüències encara poc conegudes. Si per a alguns el consum de tabac era immoral i perniciós, i per tant, demonitzat, per a altres autors seria no un vici sinó un recurs que podia contribuir amb èxit per al tractament de malalties.

Paraules clau: moral, medicina, tabac, autors, conceptes i usos. 
«Todo está hediendo a Tabaco que es lo peor olor; y con todo tiene tal eficacia para enviciar a quien le toma que son raros los que no están tocados, e q a todas horas les solicita su ansia (...) Y así aquella tuerca interior que sienten los Tabaquistas, que les impele a tomarlo, no es tuerca (...) sino de la mala costumbre, la cual quien duda que pueda estar sin que intervenga pacto con el Demonio, implícito, o explícito».

Chocolate y tabaco: ayuno eclesiastico y natural: si este le quebranta el chocolate y el tabaco al natural, para la sagrada comunión... Tomás Hurtado (1589-1659) - [1645?]

\section{TABACO, MORAL Y MEDICINA EN LA EDAD MODERNA}

Hay que decir que los dos temas clave comentados en este texto han sido ya señalados y discutidos por la historiografía tradicional y por autores de distinta formación científica, como nos da cuenta un breve recorrido bibliográfico. Desde luego con los estudios clásicos de Rodríguez Gordillo, Pérez Vidal, ${ }^{2}$ o González Enciso, ${ }^{3}$ pero también con las aportaciones de Micheli, ${ }^{4}$ del escritor Gately, ${ }^{5}$ de Belvis-Costes, ${ }^{6}$ o de Rodríguez de la Flor. ${ }^{7}$

1 RODRÍGUEZ GORDILLO, José Manuel (1990), "El tabaco del uso medicinal a la industrialización", en La Agricultura Viajera, Real Jardín Botánico, Madrid.

2 PÉREZ VIDAL, José (1959), España en la historia del tabaco, Consejo Superior de Investigaciones Científicas, Madrid.

3 GONZÁLEZ ENCISO, Agustín y TORRES, Rafael (1999), Tabaco y economía en el siglo XVIII, Universidad de Navarra, Pamplona.

4 MICHELl, Alfredo de (2015), "El tabaco a la luz de la historia y la medicina", Archivos de Cardiología de México, vol. 85/4, pp. $318-322$ [http://dx.doi.org/10.1016/i. acmx.2014.12.012.]. 
La difusión del consumo de tabaco en diferentes contextos geográficos y sociales tuvo repercusiones culturales inevitables. La percepción de un nuevo hábito provocó reacciones contradictorias e incluso extremas. Fuese en círculos cortesanos, en capas sociales más bajas o en medios eclesiásticos (seglares o regulares), el tópico tampoco se quedó al margen de la discusión moral, religiosa o medicinal. Desde emprano fue objeto de medidas excluyentes, permisivas o de aceptación moderada. Así como de obras literarias de recorte médico y otras, de manos de arbitristas, llenas de opiniones que sus autores tenían por muy fundamentadas.

En 1604, año de su ascensión al trono, el rey Jacobo I de Inglaterra escribió un corto panfleto contra el tabaco A Counterblaste to Tobacco. En su texto el monarca hablaba de consecuencias dañinas para el cerebro y los pulmones, lo que hoy parece muy actual. Además, intentando buscar el apoyo de los científicos y académicos el rey organizó una sesión en la universidad de Oxford para poner en evidencia los males del consumo de tabaco.

En los definitorios y constituciones de las comunidades religiosas la cuestión del uso del tabaco pasa a ser un tema presente, con consejos e instrucciones claras de observancia e incluso amenazas para quien incumpliese las reglas. Además, las órdenes monásticas (masculinas o femeninas) por su constante y desafiante desobediencia a las determinaciones regias y de sus superiores, eran consideradas como auténticos "nidos de sinvergüenzas". Por eso, para obispos, arzobispos, padres-generales y nuncios apostólicos ha sido un dolor de cabeza y pretexto para intensa correspondencia diplomática entre las Coronas de Portugal e España con la Santa Sede en Roma. "Religioso, ü Donato que tomare tabaco en Comunidad de Religiosos, ayune tres días a pan y agua en tierra y si le tomare delante de algún seglar, ayune dos días. Pero tabaco en humo no se tome sin grandísima necesidad y no sea en celda, ni dormitorio sino en lugar muy retirado donde no se inficione el Convento. Y el que le tome de olor, ó tabaquera se le quite el Prelado y le castigue con una diciplina $[\text { sic }]^{\prime \prime}{ }^{8}$

5 GATElY, lan (2003), La Diva Nicotina. Historia del Tabaco, Ediciones B, Barcelona.

6 BELVIS COSTES, Francesc Xavier (2010), "HABITUS TABACI. Un análisis estructural de los discursos sobre el tabaco cuando su introducción en España (1500-1700)", Revista de Antropología Experimental, $\mathrm{n}^{\circ} 10$, pp. 257-280 [https://revistaselectronicas.ujaen.es/index.php/ $\mathrm{rae} /$ article/download/1952/1701/1.

7 RODRÍGUEZ DE LA FLOR, Fernando y LABRADOR, Germán (2007), "Baroque Toxicology: Discourses on Smoke and the Polemics of Tobacco in 17th Century Spain", South Atlantic Review, vol. $72 / 1$, pp. 112-142. 
La percepción que se tenía de esa costumbre indujo diferentes formas de tratar el problema, desde el punto de vista moral, sus posibles implicaciones y consecuencias, o métodos de procedimiento pensados para resguardar consciencias.

Si, por ejemplo, para unos:

"«Pulvis eris et en pulveris reverteris»", no era escusa (sic) para que un sacerdote pusiera los polvos de tabaco en sus narices, porque ofende a Dios que los sacerdotes con esas mala yerba toquen el pan y el vino de la Eucaristía".?

Otros, más tolerantes, pero sin dejar la prudencia, admitían que a la cuestión: "El tomar tabaco en hoja, o polvo impide la Misa y Comunión ?», se podría contestar distinguiendo situaciones:

"En polvo no, por que no se toma por modo de comida, ó bebida. En hoja por la boca, sino ay cuydado de expeler la saliva porque entra en ele estomago por modo de comida, y de medicina, por las narices no ay este peligro". ${ }^{10}$

8 Constituciones y estatutos de la provincia de San luan Bautista de los Religiosos Menores Descalços de la Regular Observancia de N. P. San Francisco hechos por el Discretorio della y aprovados por su Difinitorio; dispuestos y ordenados y dados a la estampa por el Ministro Provincial, Difinitorio y Padres de dicha Provincia..., 1658.

9 RAMÓN, Fray Tomás (1635), Nueva Pragmática de Reformación, Zaragoza, apud ORTIZ, Fernando, Contrapunteo cubano del tabaco y el azúcar (1987), Fundacion Biblioteca Ayacuch, p. 260.

10 ESCOBAR Y MENDOZA, Padre Antonio de, Examen y practica de confesores y penitentes: en todas las materias de la theologia moral su autor el... de la Compañia de lesus ... (1635), Zaragoza [fig. 1]. El libro en español titulado Examen de confesores recibe su "Licencia y tasa" en Pamplona el 19 de marzo de 1628, y ya impreso la "Fe de erratas" es dada en la Compañía de Jesús de Pamplona el 23 de marzo de 1628. 
$\mathrm{Ni}$ todos eran tan condescendientes en su pensamiento. Ildefonso Vereterra y Labayru, hace notar, en 1746, que:

"La Sagrada Congregación de Cardenales y los Concilios Provinciales prohíben con gran rigor el uso del tabaco antes de celebrar, o comulgar; $\mathrm{Ni}$ es licito tampoco el tomarle en los Coros, ni Templos, por la irreverencia que se hace á tan sagrados lugares". ${ }^{11}$

El consumo de tabaco se generalizó en los monasterios y conventos femeninos, y las abadesas ofrecían tabaco a las monjas en Navidad, Año Nuevo, Día del Rey, Día de la Madre y otros más. Muy curioso es el caso de la Madre Rosa de Jesús [? -1726] de quien se decía que era muy dedicada a Nuestra Señora y a la Santidad y Virtudes. Murió con todos los sacramentos, además de rumor de predestinación. Pues, según la tradición, cuando el día de Santa Bárbara, salía de las Matinales, pidió tabaco a una monja diciendo que era la última vez que lo hacía, porque sabía que iba a partir para Dios. Esa misma noche dio el alma al Criador. ${ }^{12}$

El hábito del humo en el contexto religioso femenino, este no fue caso único. Hay muchos otros testimonios de la práctica de tomar tabaco y de circunstancias que quedaban en la memoria de presuntos testigos.

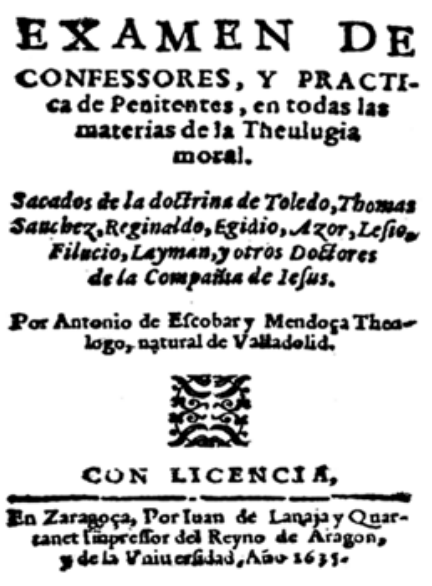

Fig. 1. ESCOBAR Y MENDOZA, Padre Antonio de, Examen y practica de confesores y penitentes: (1635). 
Sobre la Venerable Isabel de Jesús, se refiere, que:

"la apareció a esta Sierva de Dios un Sacerdote difunto, y le dijo: Que padecía muchos, y graves tormentos en el Purgatorio, por el mucho tabaco, que había tomado (...). Apareciéndosela otra Alma del Purgatorio., la encargó que escribiese, lo perjudicial que es este vicio porque son muchas las Almas atormentadas en el Purgatorio por el vició de tomar tabaco". ${ }^{13}$

Aún un ejemplo del impacto que solía tener el vicio del humo en las consciencias del clero femenino, ahora con imbricaciones de un carácter más pecaminoso e incluso sensual. El caso de Sóror Isabel do Menino Jesús, (1673-1752), una monja portuguesa que fue abadesa del Monasterio de Santa Clara, de Portalegre:

"Estando em Orasam foy auizada pedise pela Alma de outra Religioza morreo esta na flor de sua ydade e poucos annos de Profisam e pasados oyto mezes dipois de sua morte (...) foy Auizada pedise por esta alma que estaua tendo o seu purgatorio Em hum lugar tam estreito como he huma caxa de tabaco aonde padesia tirriveis tormentos procurei a cauza deste purgatorio foy o Senhor seruido darme a emtemder que hera porque tomara tabaco da caxa de hum homen e que nela ficara prezo o corasam, castiga Deus tanto suas espozas que tomam amor a homens que a sua justisa a mandou meter no fundo da terra em lugar que fose semelhante em que tinha cometido sua culpa $(\ldots)^{\prime \prime} .{ }^{14}$

11 VERETERRA Y LABAYRU, Ildefonso (1746), Despertador de dormidos, y descuidados. Desvelos de el alma, deseosa de servir a Dios, y salvarse con diversos medios, y maravillosos ejemplos, que mueven a evitar los vicios, y practicar las virtudes.

12 SANTOS, Maria Luísa Gil dos, (2000), O ciclo vivencial do mosteiro de Nossa Senhora da Assunção de Tabosa, Universidade do Porto, Porto.

13 VERETERRA Y LABAYRU, Ildefonso (1746), Despertador de dormidos.

14 Câmara Municipal de Marvão (CMM), Soror Isabel do Menino Jesus, "Carta à Abadessa e Religiosas", in Vida da Venerauel Madre Izabel do Menino Jezus, (mss.), p. 53, §5. 


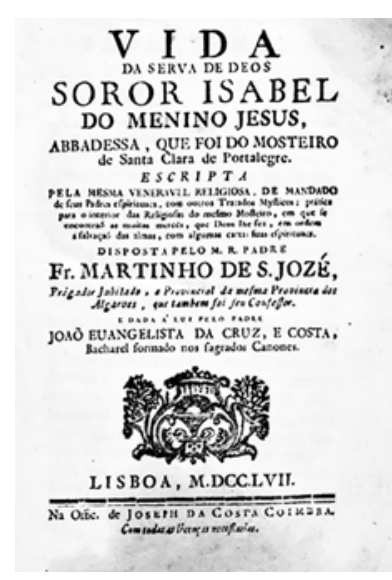

Fig. 2. S. JOSÉ, Frei Martinho de. Vida Da Serva De Deos Soror Isabel Do Menino Jesus, Abbadessa, que foi do Mosteiro de Santa Clara de Portalegre. Escripta pela mesma veneravel religiosa, de mandado de seus Padres espirituaes, com outros Tratados Mysticos;... Disposta pelo M. R. Padre Fr. Martinho de S. Jozé,.... e dada á luz pelo padre João Evangelista da Cruz, e Costa. Lisboa, 1757. Na Offic. de Joseph da Costa Coimbra.

Hay que reconocer que la existencia de registros en los libros de visitas conventuales, que prohíben el tabaquismo, aunque recurrentes, no significaba que fueran respetados dentro de estas comunidades femeninas. Todos los pretextos eran válidos para garantizar no sólo un "vicio" de consumo personal, sino también una fuente de ingresos nada depreciable.

La Madre Dionisia de San José, del monasterio de Santa Ana, en Viana do Castelo, en Alto Miño, Portugal, contribuyó a las obras del edificio conventual, incluido el dorado de las tallas, con 150.000 reis de tabaco que tenía en ese momento, pues lo hubiera plantado (el tabaco) antes de "prohibido por V. Reverendissima" (el arzobispo de Braga). ${ }^{15}$

Explicación dada en el discurso de una visita, que no tenía correspondencia con la verdad, sino que calmaba las conciencias. A pesar de las advertencias, las monjas de muchas regiones de Portugal no sólo plantaron tabaco sino que lo vendieron en los portales de los conventos, mostrando una gran resistencia a acatar lo que las autoridades seculares y eclesiásticas intentaron hacer cumplir.

15 Archivo Distrital de Braga (ADB), Fundo Monástico, Mosteiro Santa Ana, Tesoureira, $\mathrm{n}^{\circ} 44$ fls. $41 / 50$ 
Así, por ejemplo, en 1691 se construyó una nueva puerta de entrada en el monasterio de S. Denis de Odivelas (Lisboa), con una rueda destinada a la entrega de cartas y la venta de dulces y que también sirvió durante mucho tiempo como lugar de ventas ilegales de tabaco.

En 1700, el procurador de la Hacienda, en consulta al tribunal de la Junta de la Administración del Tabaco (creado en 1674), declaró que no había convento en Lisboa y en el reino (Portugal) donde no se vendiese tabaco, por la mitad (o menos de la mitad) de los precios justos. ${ }^{16}$

En materia de explicaciones para justificar las ilegalidades, Portugal no era más imaginativo que España y la justificación para la siembra de matas de tabaco, para uso solamente medicinal, era común en los Reinos.

"(...) el abuso de algunas Comunidades Religiosas en la siembra del tabaco en sus huertas ó cercados, pues sin embargo de no poder ignorar los Prelados las estrechas órdenes de S. M. para que en estos Reynos no pueda persona alguna sembrar, moler; ni fabricar el tabaco en mucha, ni corta cantidad, se ha reconocido y modernamente comprobado el abuso de algunas Comunidades Religiosas y de sus particulares individuos, con que en las huertas y cercados de sus Conventos sembraban y conservaban excesivas porciones de matas de tabaco, prevalidos sin duda de la permision (...) dispensada á las Comunidades Religiosas de poder tener en sus Conventos y casas hasta seis matas del mismo tabaco, para solo el efecto de medicinarse $(\ldots)^{\prime \prime} \cdot{ }^{17}$

Sin embargo, no todo el tabaco era consumido por las monjas, sino que también se destinaba para regalos a sacerdotes, fiscales, supervisores, médicos y como pago a los trabajadores de la cerca conventual.

El 11 de abril de 1771, las Clarisas de Funchal (Isla de Madera) registraron $26 \$ 000$ reis por la compra de tabaco, parcialmente gastados con el pago a los sacerdotes en el funeral de la Madre Ana Vitória y el sacerdote diácono, el octavo día y en la fiesta de S. María Magdalena. ${ }^{18}$

16 Archivo Nacional Torre Tombo (ANTT), Junta Administração Tabaco (JAT), Avisos, Mç. 57.

17 LA RIPIA, Juan de (1736), Práctica de la Administración y Cobranza de las Rentas Reales Y Visita De Los Ministros, Que Se Ocupan En Ellas, Imprenta de el Convento de la Merced, a costa de Lorenzo Cardama, 1736, vol. 5.

18 ANTT, Convento Santa Clara, Funchal, liv. 53, fl. 10. 
Todas estas cuestiones llamaban la atención no sólo de las autoridades sino de los eruditos, para quienes todo podía tener connotaciones, además de morales, también sociales. Fray Benito Jerónimo Feijoo y Montenegro (Casdemiro 1676 - Oviedo, 1764), no se cohibió de hacer críticas contundentes, con tintes elitistas, "a través de un tipo de literatura característico de la llustración como es el epistolar, las Cartas eruditas y curiosas inventan un modo más moderno y conversacional de implicar al lector en una curiosa indagación" 19 reconociendo que:

"No es cosa insufrible ver á un Párroco, o á otro Eclesiástico, también muy inferior al Orden Episcopal, sacar jactanciosamente la caxa de oro en un corrillo para dar tabaco (...)".

En lenguaje aparentemente piadoso, remataba:

"O cuanto celebraría yo, que en tales casos se hallase presente un Varón de zelo Apostólico, para representar al desvanecido Eclesiástico, que en el tabaco contemplase que había de ser polvo como él algún día". 20

Sin embargo, el mismo autor, no se mostraba intimidado por exhibir sus conocimientos de experto en materia de tabaco e incluso su preocupación por su reparto según criterios rígidos, incluso paradójicos (o al final coherentes) a luz del apartado a que se hizo referencia.

Véase, entonces, con sus propias palabras, este pasaje que es toda una gramática social y hasta dudosa desde una mirada cristiana:

19 RUIZA, M., FERNÁNDEZ, T. y TAMARO, E. (2004), "Resumen de Cartas eruditas y curiosas, de Benito Jerónimo Feijoo" en Biografías y Vidas. La enciclopedia biográfica en línea.

[https://www.biografiasyvidas.com/obra/cartas_eruditas.htm (1 de abril de 2020)].

20 FEIJOO, Fray Benito Jerónimo (1765), Cartas eruditas, y curiosas, en que, por la mayor parte, se continúa el designio del Theatro critico universal:impugnando ó reduciendo a dudosas, varias opiniones comunes / escritas por ... , Imprenta de D. Gabriel Ramírez., Madrid. 
"El Tabaco ciertamente es de bella calidad; y a mi parecer tan bueno, si no es mejor, que el que V. md. me remitió por Enero, y de el cual tengo alguna pequeña porción; porque en la especie de Tabaco, con el que logro muy de mi gusto, observo una estrecha economía. La contingencia de no hallar después otro igual, me hace detenido en su consumo. De suerte, que casi es menester, ó el motivo de especial benevolencia, ó el de urbanidad inexcusable, para franquear una, ü otra caxa. Fuera de estos dos casos, procuro evitar la opinión de mezquino, con otro de segunda clase, que nunca falta". ${ }^{21}$ (Subrayado nuestro).

Y a concluir su raciocinio con un consejo con una nota de humor:

"Él guardar mucho tiempo el Tabaco, no lo mejora, antes le deteriora, si la custodia de él no es mucho más estrecha, que la de reos de pena capital" ${ }^{22}$

En buena verdad, no queda duda que el ilustre Fray Benito Feijoo era un conocedor de fino calibre, quizás un verdadero estudioso teórico práctico de acuerdo con sus juiciosos consejos y opiniones. Como resulta evidente en un pasaje en que no se inhibió de dejar otro reparo irónico:

"Las advertencias, que V. md. me hace para conservar, y mejorar el Tabaco, pudieran pasar por un segundo regalo, que sirve como de adjetivo á la substancia del primero, si la utilidad fuese correspondiente á la intencion (sic). Pero francamente le digo á V. m.d. que no admito sus reglas, porque no las juzgo convenientes, por mas que la comun aceptacion (sic) las haya hecho plausibles. Ninguna humedad dice bien al Tabaco, sino la de el agua simple, y natural; porque solo esta carece de todo olor. Todo otro cuerpo húmedo tiene algún olor, que, comunicado al Tabaco, le hace degenerar. (...)".

21 FEIJOO, Fray Benito Jerónimo (1765), Cartas eruditas, y curiosas, t. I, Carta XXVII, Tabaco. Economía para conservar el Tabaco, y el Chocolate. p. 213, véase en línea [http://www. filosofia.org/bjf/bjfc500.htm (27 marzo 2020)].

22 FEIJOO, Fray Benito Jerónimo (1765), Cartas eruditas, y curiosas, t. I, Carta XXVII [http:// www.filosofia.org/bjf/bjfc 127.htm (27 marzo 2020)]. 
Y prosigue con sus considerandos:

"Yo he visto, que todas estas estudiadas recetas, para humedecerle, como introducir en él unas almendras, u hojas de azelga, o tenerle en el sitio húmedo, siempre le han deteriorado algo. Al contrario, el agua simple, tengo mil Experimentos, de que no solo le humedece sin dañarle, mas conduce mucho para su conservación; porque aquella humedad - obstruye muchos poros por donde se exhalan los corpúsculos olorosos, con que los detiene dentro de el Tabaco". ${ }^{23}$

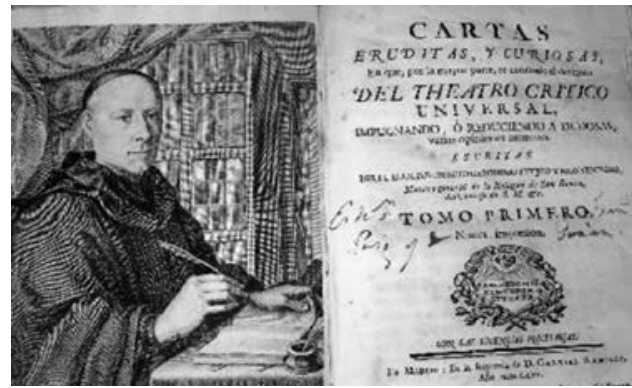

Fig.3. Dom Benito Jerónimo Feijoo e Montenegro O.S.B.

Feijoo, no fue el único eclesiástico a dejar memoria de su conocimiento sobre el tema. El cura de Fruime, D. Diego Antonio Cernadas y Castro y Ulloa (Santiago de Compostela 1702 - Fruime, La Coruña, 1777), tampoco dejó sus créditos por manos ajenas:

"El tabaco, que por acá nos administran, es muy flemático, y tan soporífero, que parece confeccionado con opio, ó aromatizado con veleño, según lo que tiene de letárgico, y es maravilla siendo como es tan seco". ${ }^{24}$

23 FEIJOO, Fray Benito Jerónimo (1765), Cartas eruditas, y curiosas, t. I, Carta XXVII [http:// www.filosofia.org/bjf/bjfc500.htm (27 marzo 2020)].

24 Obras en prosa y verso del Cura de Fruime D. Diego Antonio Cernadas y Castro y Ulloa...entre 1778 y 1781 , Madrid, por D. Joachin Ibarra. 


\section{El uso medicinal del tabaco en la tratadística}

(...) é uma das delícias, e mimos desta terra, e são todos os naturais, e ainda os portugueses perdidos por ela, e têm por grande vício estar todo o dia e noite deitados nas redes a beber fumo (...). Fernão Cardim. Tratados da terra e gente do Brasil (1601). ${ }^{25}$

Entre 1537 y 1559, las obras publicados en distintos países se referían a los usos medicinales del tabaco entre las poblaciones indígenas del Nuevo Mundo, con testimonios de su aplicación terapéutica en enfermedades corporales generales, catarros, resfriados y fiebres, ayuda a la digestión o en la prevención del hambre y la sed, o como purgante y narcótico.

Los autores que tuvieron contacto con el tabaco y cuya formación o interés los conectaba con la necesidad de difundir los conocimientos y la enseñanza de la medicina, botánica y herbaria no quedaron indiferentes ante el posible uso terapéutico de esa planta.

Algunos redactaron muchas líneas en su defensa, exponiendo con lenguaje sencillo el resultado de sus estudios, de sus observaciones empíricas y de su intuición sobre los beneficios del tabaco. Otros haciendo todo lo contrario, intentando demostrar que se trataba de un mito y producto de creencias irracionales y no verificadas científicamente. Lo cierto es que tal pugna duró mucho tiempo sin llegar a ningún consenso. Hubo las más encendidas controversias sobre la naturaleza y aplicaciones del tabaco, tanto en el terreno médico como en el jurídico-legal. ${ }^{26}$ Así lo atestigua la rica tradición tratadista. De acuerdo con una prospección bibliográfica, durante el siglo $\mathrm{XVI}$ el tabaco aparece referenciado en 60 libros europeos diferentes y en otros 350 textos (publicados o en manuscrito) sólo en la primera mitad del siglo XVII. ${ }^{27}$

25 Escrito entre los años de 1583 e 1601, su $1^{a}$ edición en Brasil ha sido en 1925 y en Portugal es de 1997, Comissão Nacional para as Comemorações dos Descobrimentos Portugueses, Lisboa.

26 GARCÍA SANTO-TOMÁS, Enrique (2010), "Los Humos del Mercedario: El Postre Americano de La Villana de Vallecas", RILCE. Revista de Filología Hispánica, vol. 26/1, pp. $62-73$.

27 BLEICHMAR, Daniela (2017), Visual Voyages: Images of Latin American Nature from Columbus to Darwin, Yale University Press, New Haven; y EGMOND, Florike (2010), The World of Carolus Clusius Natural History in the Making (1550-1610), Pickering and Chatto, Londres. 
Véase las obras variopintas en favor y en contra del tabaco, de Bartolomé Marradón (1618), ${ }^{28}$ Juan de Castro (1620), ${ }^{29}$ Francisco de Almirón y Zayas (1623), ${ }^{30}$ Pedro López de León (1628), ${ }^{31}$ Francisco de Leiva y Aguilar (1634), ${ }^{32}$ Tomás Ramón (1635), ${ }^{33}$ León Pinelo (1636), ${ }^{34}$ Bartolomé Jiménez Patón (1638), ${ }^{35}$ Tomás Hurtado (1645), ${ }^{36}$ Cristóbal de Hayo (1645), ${ }^{37}$ Miguel Rojas Soria de Campos (1655), ${ }^{38}$ Diego Henriquez Cor-

28 MARRADÓN, Bartolomé (1618), Dialogo del uso del tabaco, los daños y provechos que el tiempo y experiencia an descubierto de sus efectos, y del chocolate y otras bevidas, Herederos de Gabriel Ramos Bejarano, Sevilla.

29 CASTRO Y MEDINILLA, Juan (1620), Historia de las virtudes y propriedades del tabaco, Córdoba.

30 ALMIRON ZAYAS, Fernando de (1623), Discurso de la anothomia, de algunos miembros del Cuerpo humano, necessaria, en orden, a los daños, que del continuo uso del Tabaco, suceden en los que le usan sin orden y methodo medicinal. Com algunos avisos, y documentos, para los que le uvieren de usar, con lo qual les sera menos dañoso su uso, Imp. Gabriel Ramos Vejarano, Sevilla.

31 LÓPEZ DE LEÓN, Pedro (1628), Pratica y teorica de las apostemas en general y particular. Questiones, y praticas de Cirugia, de heridas, llagas, y otras cosas nuevas, y particulares, Oficina de Luys Estupiñan, Sevilla.

32 LEIVA y AGUILAR, Francisco de (1634), Desengaño contra el mal uso del tabaco. Tocanse varias lecciones, y tratan se al intento, muchas dudas: con resolucion las nuevas, con novedad las antíguas, Salvador de Cea Tesa, Córdoba.

33 RAMÓN, Tomas (1635), Nueva Premática de reformación,contra los abusos de los afeytes, calzado, guedejas, guarda-infantes, lenguaje crítico, moños,trajes; y excesso en el uso del tabaco, Diego Dormer, a costa de Giusepe Ginobart, mercader de libros, Zaragoza.

34 LEÓN PINELO, Antonio de (1636), Qvestion moral. Si el chocolate quebranta el ayuno eclesiastico. Tratase de otras bebidas y confecciones que se vsan en varias provincias, Viuda de Juan González, Madrid.

35 JIMÉNEZ PATÓN, Bartolomé (1638), Reforma de trages. Doctrina de frai Hernando de Talavera primer Arçobispo de Granada. Ilustrada por el maestro Bartolome Ximenez Paton, Regente del Estudio de letras umanas en Villanueba de los Infantes. Enseñase el buen uso del Tabaco, Imp. Juan de la Cuesta, Baeza.

36 HURTADO, Tomás (1645), Chocolate y tabaco, ayuno eclesiastico y natural: si este le quebrante el chocolate: y el tabaco al natural, para la Sagrada Comunion, Francisco Garcia, impressor del Reyno, Madrid.

37 HAYO, Cristobal de (1645), Las excelencias y marivillosas [sic] propiedades del tabaco, conforme a gravissimos Autores, y grandes experiencias agora nuebamente sacadas a luz: para consuelo del genero humano, Diego de Cossio, Salamanca.

38 ROJAS SORIA DE CAMPOS (1655), Miguel, Physico, y medico tratado, que propone desengaños a los que lleva dos del vulgar, y depravado uso de tomar tabaco, no previenen los daños que causa tomandolo, Juan Gomez de Bias, Sevilla. 
rea (1659), ${ }^{39}$ Juan de Reyna Monge (1661) ${ }^{40}$ y Bartolomé Zanahuja y Albacar (1698). ${ }^{41} \mathrm{Y}$ así ha continuado durante las dos centurias siguientes. ${ }^{42}$ Pionero muy conocido en los estudios de ámbito científico fue Nicolás Monardes (c. Sevilla, 1493 - Sevilla, 10 de octubre de 1588), destacado médico y botánico, cuya obra conoció una amplia divulgación. Desde luego, era un defensor de las propiedades curativas del tabaco ${ }^{43}$ al que dedicó mucha atención en La Historia Medicinal de las cosas que se traen de nuestras Indias Occidentales (1571), ${ }^{44}$ después traducida por Thomas Hackett y publicada en Londres (1596), bajo el título Joyfull Newes out of the New Found World. Decía entre otras cosas:

"Tiene esta yerba tabaco particular virtud de sanar dolores de cabeza, en especial proviniendo de causas frías; y así cura la axaqueca (sic) cuando de humor frío proviene o viene de causa ventosa; hánse (sic) de poner las hojas calientes sobre el dolor y multiplicándolas las veces que fueren menester hasta que el dolor se quite". ${ }^{45}$

39 HENRÍQUEZ CORREA, Diego, Decision del punto en que se controvierte si los polvos que de nuevo se añaden al tabaco son dañosos o provechosos, Juan Gomez de Blas, Sevilla.

40 REYNA MONGE, Juan de (1661), Para Todos El Tabaco Vedado En Su Abuso Deshecho En Poluos y En Humo Desuanecido, Juan Gomez de Blas, Sevilla.

41 SANAHUJA Y ALBACAR, Bartolomé, CASALETE, José Luca y SANZ, Vicente (1698), Satisfaccion precisa a una duda voluntaria sobre si la fabrica del tabaco puede ser nociva mediante alguna infeccion en el aire respecto a sus vecinos y a los que por alli transitaren, por las cualidades, vapores y efectos de los tabacos de hoja y polvo y sus composiciones, Zaragoza.

42 Solo un ejemplo, LAVEDAN, Antonio (1796), Tratado de los usos, abusos, propiedades y virtudes del tabaco, café, te y chocolate; extractado de los mejores autores que han tratado de esta materia, á fin de que su uso no periudique á la salud, antes bien pueda servir de alivio y curación de muchos males, Imprenta Real, Madrid.

43 MONARDES, Nicolás Bautista (1689), Delle Virtu del Tabaco. E sue grandissime, e maravigliose operationi. Tratatto nel quale ogn'uno puè cavare non poco profitto, Presso Leonardo Pittoni, Venecia.

44 MONARDES, Nicolás Bautista (1571), Segunda parte del libro des las cosas que se traen de nuestras Indias Occidentales, que sirven al uso de la medicina; do se trata del tabaco, y de la sassafras, y del carlo sancto, y de otras muchas yervas y plantas, simientes, y licores que agora nuevamente han venido de aqulellas partes, de grandes virtudes y maravilhosos effectos, Imp. Alonso Escrivano, Sevilla [https://books.google.pt/books?id=HVDo5mkqqGs$C \&$ printsec $=$ frontcover $\& h l=p t-P T \# v=o n e p a g e \& q \& f=f a l s e]$.

45 MONARDES, Nicolás Bautista (1580), Primera, y segunda y tercera partes de la Historia medicinal de las cosas que se traen de nuestras Indias Occidentales, Imp. Casa de Fernando Díaz, Sevilla, pp. 32r-39r [http://hicido.uv.es/Expo_medicina/Renacimiento/texto_monardes.html]. 
Otra de las primeras noticias de las propiedades curativas del tabaco entre los indios aparece en la obra del padre ignaciano Bernabé Cobo, Historia del Nuevo Mundo. Según el autor "son innumerables las curas que se hacen con las rayces y hojas del tabaco". ${ }^{46} \mathrm{Sin}$ embargo, el padre jesuita también llamaba la atención sobre los perjuicios que podrían resultar del uso inmoderado del tabaco.

El monje franciscano André Thevet que tuvo contacto con el tabaco en Brasil, advirtió en su obra Les singularités de la France antarctique, autrement nomée Amerique \& de plusieurs Terres \& Isles decouvert de notre temps, publicada en Amberes (1558), que fumar podría causar debilidad y desmayo. Thevet no fue el único que expresó reservas sobre la conveniencia del tabaco. Conrad Gesner, botánico, médico y científico, analizó las hojas de tabaco e en Epistolarum medicinalum, Libri 11, impreso en Zurich, (1577) informó sobre sus cualidades venenosas.

Entre 1570 y 1577, Francisco Hernández fue enviado a México por Felipe Il de España, para recoger información sobre las plantas medicinales del Nuevo Mundo. Una expedición que costó aproximadamente 80 mil ducados. En Nueva España, Hernández recopiló mucha información sobre el uso del tabaco para combatir enfermedades. El volumen de datos reunidos por la expedición de Hernández fue considerable; pero la mayor parte de la información nunca llegaría a ser publicada. ${ }^{47}$

Philaretes, un médico que escribió en Londres (1602) un libro titulado Work for Chimny sweepers or A warning for Tabacconists planteó muchas críticas, especialmente sobre el uso indiscriminado de la hierba para todas las enfermedades en todos los grupos de edad sin prescripciones específicas medidas. W. Vaughan en 1612, en su obra Directions for Health, both Natural and Artificial: derived from the best physitians as well moderne as auncient, también publicada en Londres, advirtió que "podría causar mucho daño cuando se abusa".

En fuentes portuguesas del siglo XVI, el uso médico del tabaco aparece con relativa frecuencia. En una de sus cartas, el jesuita Manuel da Nobrega (1517-1570) escribió que el humo de la hierba sagrada "ayuda a la digestión y otras enfermedades corporales y purifica la flema estomacal". ${ }^{48}$ El también ignaciano padre Fernão Cardim (1549-1625) destacó que:

46 COBO, Bernabé, Historia del Nuevo Mundo, vol. 4, p. 403.

47 GOODMAN, Jordan, Tobacco in history.

48 LEITE, Serafim, "Os jesuítas no Brasil e a medicina", Revista Petrus Nominus, Lisboa, 1936, p. 13. 
"esta erva santa serve muito para várias enfermidades, como feridas, catarros e principalmente serve para doentes da cabeça, estômago e asmáticos. Nesta terra se fazem umas cangueras de folha de palma cheia desta erva seca, e pondo-lhe fogo por uma parte põem a outra na boca, e bebem o fumo; é uma das delícias, e mimos desta terra, e são todos os naturais, e ainda os portugueses perdidos por ela, e têm por grande vício estar todo o dia e noite deitados nas redes a beber fumo, e assim se embebedam dela, como se fora vino". 49

Gabriel Soares de Sousa (1540-1591), explorador y naturalista, concejal del cabildo de Bahia, que tuvo contacto con los grupos indígenas que habitaban la costa de la América portuguesa, observó en su Tratado descritivo do Brasil (1587), ${ }^{50}$ que los colonos, por lo que aprendieron con los nativos, usaban hierba santa para matar con "(...) su jugo los gusanos que se crean en heridas y llagas de personas descuidadas (...)". ${ }^{51}$

El fraile Ives d'Évreux, (1577-1632) que estuvo en Maranhão (Brasil) en 1612 y se quedó con los indios durante más de dos años, describió las propiedades que había observado en el uso del tabaco por parte de los Tupinambás:

"Creem que esta erva os torna mais discretos, judiciosos e eloquentes, de forma que antes de começarem algum discurso usam dela; não me parece que seja, contudo, muito supersticiosa, porque há nisto uma razão natural; eu mesmo experimentei e reconheci que a fumaça esclarece o entendimento, dissipando os vapores dos órgãos do cérebro, fortalece a voz, secando a umidade e escarros da boca, permitindo assim facilidade à língua para bem exercer as suas funções... É facil experimentar isto, usando-se dela não me parece saudável aos que se alimentam de bebidas e carnes quentes, porém é útil aos que sentem frios e húmidos o estômago e o cerebro". ${ }^{52}$

49 CARDIM, Padre Fernão, Tratados da Terra e Gente do Brasil, Transcrição do texto, Introdução e Notas por Ana Maria de Azevedo, CNCDP, Lisboa, 1997.

50 En ese año el autor estuvo en Madrid y lo dio al influyente Don Cristóbal de Moura [http:// brasilhis.usal.es/pt-br/personaje/gabriel-soares-de-sousa-souza].

51 SOUSA, Gabriel Soares de, Tratado descritivo do Brasil em 1587 [http://www2.senado.leg.

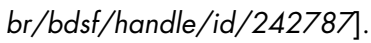


Francisco Rodrigues Cação (1614 -1666), médico del infante D. Pedro de Portugal, habrá dejado un manuscrito en contra del uso del tabaco en tono muy crítico y contundente llamándole veneno fino y peste encubierta. ${ }^{53} \mathrm{No}$ que no deja de ser irónico, pues el entonces infante, más tarde rey $D$. Pedro II, fue quien ordenó la institución de la Junta do Tabaco.

Ya en el siglo XVIII, el fraile boticario João de Jesus Maria (1777) enfatizó la capacidad emética y purgante de las hojas de tabaco en su manuscrito Historia Pharmaceutica das plantas exóticas, seus produtos, naturalidades e virtudes para facilitar os conhecimentos dos vegetaes (...). ${ }^{54}$

Hay que decir que "tanto el tabaco para fumar, como el rape o polvo de tabaco era de uso común en los jesuitas", 55 por eso, muchos de ellos se han ocupado del tema en sus escritos. $Y$ muy en especial los que tuvieron contacto directo con los territorios americanos de los imperios ibéricos.

Frailes, herbolarios, físicos, médicos, hasta los barberos cirujanos, fueron pues algunos de los actores sociales que dejaron en manuscritos o libros impresos sus opiniones y pareceres sobre las decantadas virtudes del tabaco o, al contrario, sobre los perjuicios de su uso y los peligros si fuera consumido de forma inmoderada.

A medida que avanzaba el siglo XVII los médicos desconfiaban cada vez más del tabaco como medicamento, pero esto no impidió que siguiera formando parte de las farmacopeas. John Wesley, en su Primitive Physick publicado por primera vez en 1747, lo recomendó para el dolor de oídos. A lo largo de la centuria siguiente los consejos para un uso clínico adecuado del tabaco van teniendo expresión exitosa e imaginativa:

52 Viagem ao norte do Brasil feita nos annos de 1613 a 1614, pelo padre Ivo d'Evreux, religioso capuchinho, publicada conforme o exemplar, unico, conservado na Bibliotheca imperial de Pariz, typ. Do Frias, 1874 [https://books.google.pt/books? id=1 HICAAAAYAAJ\&hl=pt-PT\&source $\left.=g b s \_n a v l i n k s \_s\right]$.

53 CAÇÃO Francisco Rodrigues (1614-1666), Invectiva contre o Tabaco, em que mostrava com fundamentos solidos ser peçonha fina, e peste encoberta, apud BAUDRY, Hervé, Livro médico e censura na primeira modernidade em Portugal (2017), CHAM, Lisboa.

54 Véase, a propósito, SILVA FILHO, W., A natureza brasílica nas farmacopeias do Frei João de Jesus Maria [https://www.academia.edu/27813224/A_natureza_bras\%C3\%ADlica_nas_ farmacopeias_do_Frei_Jo\%C3\%A3o_de_Jesus_Maria].

55 FERRER BENIMELI, José Antonio (1996), "Viaje y peripecias de los jesuitas expulsos de América. (El Colegio de Córdoba de Tucumán)", Revista de Historia Moderna, vol. 15, pp. 149-177 (p. 174). 
"Una tintura hecha con tabaco y orina de niño mata a los gusanos y destruye los piojos, chinches.

Con yema de huevo, muy util para derrame cerebral, epilepsia y letargo, mientras que la pipa preservaba a los marineros del escorbuto, siempre y cuando se hiciera la frotación con el tabaco de España.

El humo de tabaco conviene también para purificar el aire en las enfermedades contagiosas, como antiséptico puede ser utilísimo, en inyección, en las ulceras fistulosas; y una ayuda en el retroceso de las viruelas". ${ }^{56}$

El uso de ciertos aparatos para hacer la fumigación, con tabaco, se pondrán muy de moda. Como, por ejemplo, el aparato ideado por Cristóbal Fabregat ${ }^{57}$ para reanimar ahogados, intoxicados por exhalaciones y helados. Su trabajo se considera como el mejor estudio monográfico sobre la reanimación, publicado en España a lo largo del siglo XVIII.

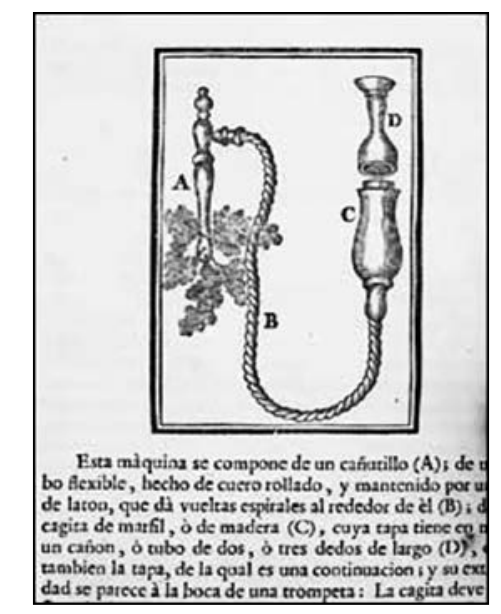

Fig.4. Aparato ideado por Cristóbal Fabregat.

Fuente: http://hicido.uv.es/Expo_medicina/lustracion/piquer.html

56 Discurso medico practico sobre el modo de socorrer, y revocar a sus sentidos a los ahogados, ahorcados, elados y sufocados por el tufo del carbon, de la cal, de las velas de sebo, y de otras exalaciones perniciosas... / compuesto por ... Christoval Fabregat, medico del Claustro y Universidad de Valencia, 1755 [http://www.cervantesvirtual.com/obras/autor/fabregat-cristobal-25596].

57 Cristóbal Fabregat y Forés, Benassal (Castellón), 13.10.1734 - Valencia, 23.12.1809. 
Se entusiasmaron pronto los médicos europeos del siglo XVIII. Opinaban que los intestinos por su situación y organización podían reavivar la sensibilidad casi perdida del todo y que, por lo tanto, insuflar aire caliente, algo áspero como el humo de tabaco, era un socorro muy eficaz y que se debía usar sistemáticamente. Los éxitos conseguidos por aquel procedimiento menudearon, atestiguados por una multitud de observadores de varios países. Con sólo dos pipas, un encendedor y tabaco, se podía socorrer inmediatamente al ahogado, lo que era esencial.

El tubo de una pipa se introducía en el ano, mientras que, sobrepuestas las dos cazoletas, alguien soplaba el humo por la segunda pipa. Era, desde luego, un sistema muy rudimentario que tenía sus inconvenientes y mucha incomodidad. ${ }^{58}$

Como se ha señalado, la publicidad de los buenos resultados obtenidos con ese método ultrapasará fronteras, caso de Francia, en que se recomendaba:

"Para los ahogados, armar la pipa y encender el tabaco que se habrá puesto en ella; y luego que está encendido se introduce la cánula en el ano del ahogado después se mete en esta el extremo del tubo flexible y se empieza a soplar en la pipa por el segundo tubo. Así se continúa soplando hasta que se consume todo el 'tabaco, y no se deja de introducir el humo en los intestinos del ahogado hasta que da señales de vida, ciertas y permanentes". ${ }^{59}$

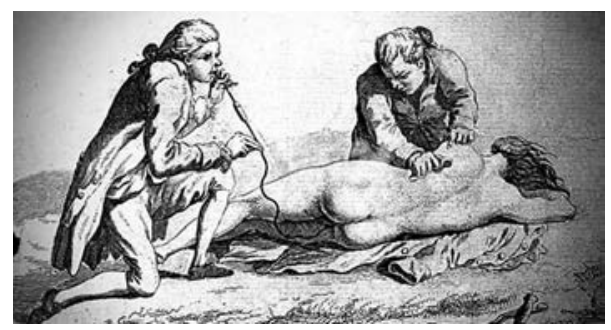

Fig.5. Enema de humo de tabaco

Ilustración: The Wellcome Collection (CC BY 4.0).

58 DEMERSON, Paula de (2001), "Muertes aparentes y socorros administrados a los ahogados y asfixiados en las postrimerías del siglo XVIII", Asclepio, vol. LIII/2, [http://asclepio.revistas. csic.es/index.php/asclepio/article/download/159/156].

59 Tratado de las enfermedades mas frequentes de las gentes del campo / pour Mr. Tissot (1776). 
Richard Mead (1673-1754), médico de Londres, graduado de la Universidad de Padua (1695) fue médico de los reyes Jorge I y Jorge II, la reina Ana, Isaac Newton y otras personalidades británicas. En 1702 publicó un trabajo de referencia Accidentes mecánicos de venenos, en el cual recomendó la infusión rectal de humo de tabaco. ${ }^{60}$

En 1767, se fundó en Amsterdam la primera asociación civil dedicada al salvamento de las personas ahogadas (Society for Recovery of Drowned People). La Sociedad recomendó, entre otros métodos, la introducción de humo de tabaco en el recto o, si no resulta en la administración de enemas de infusión de tabaco. Cuatro años después ya contaba con 150 pacientes salvados, allegadamente gracias a este método.

La "Sociedad Real Humana de Inglaterra" se fundó en Londres en 1774 y uno de sus miembros describió el equipo y su forma de uso:

"Tienen una cápsula de hierro o latón lo suficientemente grande como para contener aproximadamente media onza de tabaco a la que se atan las cápsulas, dos tubos, uno insertado en el ano y el tubo opuesto está hecho como el extremo de la trompeta que es aplicado a la boca y hecho de marfil, el paciente o un asistente pueden soplarlo y forzar el humo del tabaco quemado en la cápsula hacia el ano. De esta manera, el humo debe volar el ano hasta que el paciente reciba el estímulo suficiente para excitarlo a defecar". ${ }^{61}$

Otro clínico Walter Cogan (1736-1818), describió varios métodos de reanimación, fricción, fumigación, introducción de humo de tabaco en el recto. Este médico y William Hawes, fundaron la Institution for Affording Immediate Relief to Persons Apparently Death from Drowing, después llamada Society for the Recovery of Person Apparently Drowned, con el objetivo de ayudar a las personas que se cayeron al río Támesis.

No es de extrañar, pues, que los miembros de la sociedad hayan distribuido esa tipología de equipo a lo largo de las orillas del río Támesis, que se usaría hasta las dos primeras décadas del siglo XIX.

60 HATTIE, W. H. (1928), "Richard Mead: A Father of Preventive Medicine", Canadian Medical Association Journal, vol. 19/1, pp. 101-103.

61 PURCE, G.R.B. (1947), "Some aspects, historical and otherwise, of surgery of the thorax", The Ulster Medical Journal, vol. 16/2, pp. 87-101. 


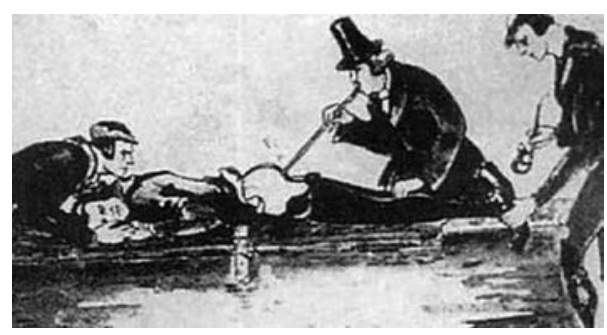

Fig.6. Enema de tabaco

Fuente: https://www.interesly.com/tobacco-smoke-enema-blows/

El método sería abandonado no sólo por, al finalmente, haberse constatado su ineficacia sino también porque se aisló la nicotina, siendo considerada tóxica. En 1811, Benjamin Brodie, demostró que la nicotina era un tóxico cardíaco, lo que condujo gradualmente al abandono de este método de reanimación. ${ }^{62}$

En 1835, la Revista Médica Fluminense publicó con el título Memoria sobre el tabaco, una serie de conferencias leídas en las sesiones del 6 y 18 de septiembre de 1834 en la Sociedad de Medicina de Río de Janeiro por Emilio Joaquim da Silva Maia, un respetado médico de la corte. En su texto el autor da cuenta de un episodio muy poco afortunado en el que, a su modo, también ilustra el abandono de tal práctica:

"Md. ${ }^{a}$ de Saint Tronel, sujeita à lombrigas, consultou para isto à hum Charlatão de Tirlemont (Bélgica). Este aconselhou-a que tomasse duas oitavas de tabaco de fumar, que o posesse em infusão em oito onças de água, para fazer um clystel. Esta Sra. querendo ficar certa de ter destruído o inimigo, que a atormentava, havia muito tempo, em lugar das duas oitavas tomou duas onças de tabaco o mais forte, e em lugar de fazer uma simples infusão, o submmeteu à uma ebulição muito longa. O cosimento he injetado no recto. No mesmo instante esta Sra. grita, que estava no estado mais singular, que se achava como ébria, e immediatamente more".

Curiosamente, con el incremento de detractores del uso del tabaco para fines medicinales, casi se vuelve en paradoja que las escuelas de medicina portuguesas tengan una historia vinculada al consumo de este género.

62 EINSENBERG, Mickey S., BASKETT, Peter y CHAMBERLAIN, Douglas (2007), "A History of Cardiopulmonary Resuscitation", en Cardiac Arrest The Science and Practice of Resuscitation Medicine, Norman Paradis. Cambridge University Press [https://www.aped-dor.org/images/ diversos/documentos/a_luta_contra_a_dor_e_o_sofrimento.pdf]. 
En 1825, el cirujano honorario del rey D. João VI, Teodoro Ferreira Aguiar, intercede a favor de un asentista de tabaco que había sido arrestado por el Intendente General de la Policía. El hombre es liberado y, como muestra de agradecimiento al cirujano, decidió ofrecerle una suma de diez contos de reis. Ferreira de Aguiar rechaza la oferta y sugiere que se la ofrezca al rey para que pueda crear dos escuelas de cirugía. Los asentistas de tabaco, posteriormente, otorgarán luego otorgan un presupuesto anual, como subsidio para el funcionamiento de las escuelas. Así se crearon la Régia Escola de Cirugia do Porto en el Hospital de Santo Antonio, y la Régia Escola de Cirurgia de Lisboa, en el Hospital de San José. ${ }^{63}$

Sea como sea, hay que reconocer que a pesar de los alegados méritos o deméritos del uso del tabaco, lo cierto es que su presencia en los tratados medicinales y morales ha sido una constante a lo largo de siglos y como ha planteado Francisco de Leyva:

"yerba tan usada de todas suertes de personas: pues del Soldado al Estudiante, del Religioso al Secular; del ciudadano al mítico, del plebeyo al noble, del muchacho al viejo apenas ay quien no lo aya probado, y usándolo los mas, quien pues se ha de oponer á opinión tan común, que vivan tantos engañados?". ${ }^{64}$

En conclusión, lo cierto es que no hay duda que la propagación del consumo de tabaco, en sus diversas formas, se extendió a todas las clases sociales y en el siglo XVIII fumar era el vínculo intercultural más común entre todos los pueblos europeos. Aunque con características distintas y codificación social. Rapé, pipa, humo en hoja pautaban las reglas y prácticas de los diversos grupos estamentales y señalaban códigos de distinción.

Para unos, no fue más que un vicio detestable, o incluso un pecado; para otros era tan sólo una medicina distinta de los productos de las boticas. Defensores y detractores se han confrontado en el campo de la ciencia, de la moral y de la religión, sin olvidar los arbitrios que subrayaban la importancia del tabaco para la fiscalidad y economía de los territorios y

63 FRAGA, Sílvia (2010), "Tabaco: panaceia no Século XVI e patologia no Século XX", Acta Medica Portuguesa, vol. 23/2, pp. 243-246.

64 LEIVA Y AGUILAR, Francisco de (1634), Desengaño contra el mal uso del tabaco: tocanse varias lecciones y tratanse al intento, muchas dudas, con resolucion las nuevas, con novedad las antiguas por el doctor Francisco de Leiva y Aguilar, medico philosopho... 
unidades políticas en las cuales se desarrolló como monopolio o por explotación directa.

Tampoco es posible concebir el uso indígena de la planta de tabaco sin comprender su inserción en las prácticas medicinales, resultantes de un conocimiento empírico, su sesgo cultural, parte inseparable de los principios que reglaban los sistemas religiosos indígenas y componente fundamental de muchos rituales. Saberes cuya divulgación se ha hecho por mano de viajeros, eclesiásticos, exploradores, botánicos, médicos, miembros de cuerpos administrativos coloniales y otros actores sociales. 